\title{
Characteristics of children consulting for cough, sore throat, or earache
}

\author{
Johannes HJM Uijen, Huug J van Duijn, Marijke M Kuyvenhoven, \\ François $G$ Schellevis and Johannes $C$ van der Wouden
}

\section{ABSTRACT \\ Background \\ GPs are often consulted for respiratory tract symptoms} in children.

Aim

To explore characteristics of children, their parents, and their GPs that are correlated with consulting a GP for cough, sore throat, or earache.

Design of study

Second Dutch National Survey of General Practice (DNSGP-2) with a health interview and an additional questionnaire.

Setting

Children aged 0-17 years registered with 122 GPs in Dutch general practice.

Method

Characteristics of patients and their GPs were derived from the DNSGP-2 health interview and a

questionnaire, respectively. Characteristics of the illness symptoms and GP consultation were acquired by means of an additional questionnaire. Data were analysed using multivariate logistic regression.

\section{Results}

Of all children who completed the questionnaire, 550 reported cough, sore throat, or earache in the 2 weeks preceding the interview with 147 of them consulting their GP. Young children more frequently consulted the GP for respiratory symptoms, as did children with fever, longer duration of symptoms, those reporting their health to be 'poor to good', and living in an urban area. When parents were worried, and when a child or their parents were cued by someone else, the GP was also consulted more often. GP-related determinants were not associated with GP consultation by children.

\section{Conclusion}

This study emphasises the importance of establishing the reasons behind children with respiratory tract symptoms consulting their GP. When GPs are aware of possible determinants of the decision to consult a GP, more appropriate advice and reassurance can be given regarding these respiratory symptoms, which are generally self-limiting.

Keywords

children; consultation; family practice; respiratory tract infections.

\section{INTRODUCTION}

Respiratory tract symptoms such as cough, sore throat, and earache are common in children. ${ }^{1}$ Most illnesses in children are resolved without involving the professional healthcare system. Children consult their GP in only $11 \%$ of all illness episodes, ${ }^{2}$ while respiratory symptoms account for a quarter of the consultations by children in general practice. ${ }^{3}$

Respiratory tract symptoms generally have a viral cause and are self-limiting. ${ }^{4-7}$ Accordingly, the Dutch guidelines recommend that GPs should provide adequate information to parents and children. ${ }^{8-10}$ Children (and/or parents) and GPs seem to have different expectations for consulting a GP. Contrary to what many GPs believe, patients consult a GP primarily for information and reassurance rather than for a prescription for medication. ${ }^{11,12}$

Patients (more than GPs) regard respiratory tract symptoms as serious, and generally believe consulting a health professional is necessary for these symptoms. ${ }^{13}$ Although inconsistent with the previous observation many adult patients believe that antibiotics are essential to treat respiratory infections, Van Duijn et al found that adult patients with respiratory symptoms for longer than 2 weeks

JHJM Uijen, MD, GP; JC van der Wouden, PhD, senior lecturer, Department of General Practice, Erasmus MC, University Medical Center, Rotterdam; HJ van Duijn, $P h D$, MD, GP; MM Kuyvenhoven, PhD, MD, senior lecturer, Julius Centre for Health Sciences and Primary Care, University Medical Center, Utrecht. FG Schellevis, PhD, MD, professor of general practice, NIVEL, Netherlands Institute of Health Services Research, Utrecht, and Department of General Practice EMGO Institute, Free University Medical Center, Amsterdam, the Netherlands.

Address for correspondence

Dr Johannes HJM Uijen, Department of General Practice, Room Wk 131, Erasmus MC, University Medical Center, Rotterdam, PO Box 2040, 3000 CA Rotterdam, the Netherlands. E-mail: j.uijen@erasmusmc.nl

Submitted: 3 December 2007; Editor's response: 23 January 2007; final acceptance: 21 January 2008.

(c)British Journal of General Practice 2008; 58: 248-254.

DOI: 10.3399/bjgp08X279751 
more frequently visited their GP when they were cued by others. In addition, patients who perceived their symptoms as more serious, and those who were unaware of the self-limiting nature of respiratory symptoms more frequently visited their GP. ${ }^{14}$

Although these determinants have been studied in adults, it is unknown whether parents and their children have the same expectations regarding GP consultation for a child's respiratory tract symptoms.

Although van Duijn et al found no association between GP-related determinants and illness behaviour in cases of respiratory tract infection, ${ }^{14}$ other studies have reported that GP-related characteristics (such as GP's age and sex) correlate with consultation behaviour. ${ }^{15-17}$

Less is known about which GP-related determinants influence GP consultation for respiratory tract symptoms among children. This study explores determinants of a GP consultation with respect to children, their parents and their GP, with regard to consulting a GP for cough, sore throat, or earache.

\section{METHOD}

\section{Design}

The data used in this study were derived from the Second Dutch National Survey of General Practice (DNSGP-2), which was performed by the Netherlands Institute for Health Services Research (NIVEL) in 2001. ${ }^{18}$

To establish the factors that determine which children with respiratory symptoms are presented to their GP, the characteristics of children reporting their symptoms in a health interview and subsequently consulting their GP were compared with children who also reported these symptoms but did not consult their GP. GP characteristics for these two groups were also compared to determine whether or not they might be related to consultation behaviour.

\section{Second Dutch National Survey of General Practice}

During a 1-year study period, 195 GPs in 104 practices throughout the Netherlands participated in the data collection. In the Netherlands, general practices have a fixed patient list, all inhabitants are listed in a general practice, and GPs have a gatekeeping role for specialised care. The patients enlisted in the participating practices were comparable to the general Dutch population with respect to age, sex, and type of health insurance. Data also included all prescribed medication.

For the current analysis, data from 23 practices were excluded because data were incomplete, or linking additional child questionnaires (see 'Patients' paragraph) to GPs failed. Data were included from

\section{How this fits in}

Respiratory tract symptoms are common in children. Adult studies show that older age, worry, and being cued by others correlate with the consulting of a GP for these symptoms; the present study revealed similar results for children. In addition, it was found that fever, longer duration of symptoms, and higher level of urbanisation play an important role in why patients consult their GP. There is a strong association between being cued by others and GP consultation, but GP-related determinants are not associated with the decision to consult the GP for respiratory tract symptoms.

the child patients of 81 practices with 122 GPs (Figure 1). When comparing these 122 GPs with all 7676 Dutch GPs no significant differences were found for sex, age, and degree of urbanisation. Single-handed GPs were relatively underrepresented (34\% versus $43 \%, P=0.04$ ) among the participating GPs.

\section{Health interview}

An all-age random sample of approximately 150 listed patients per full-time equivalent GP was selected and approached to participate in a health interview: ${ }^{19}$ the response rate was $65 \%$. The interviews were performed at the patient's home by trained interviewers, and the interviews were evenly distributed over four consecutive 3-month periods. A total of 3018 children (aged 0-17 years) participated in the health interview (Figure 1). The following personal characteristics were derived from these data: age; level of education of the parents (highest education of both parents, dichotomised into lower

Figure 1. Selection of the study population (aged 0-17 years) from the Second Dutch National Survey of General Practice (DNSGP-2).

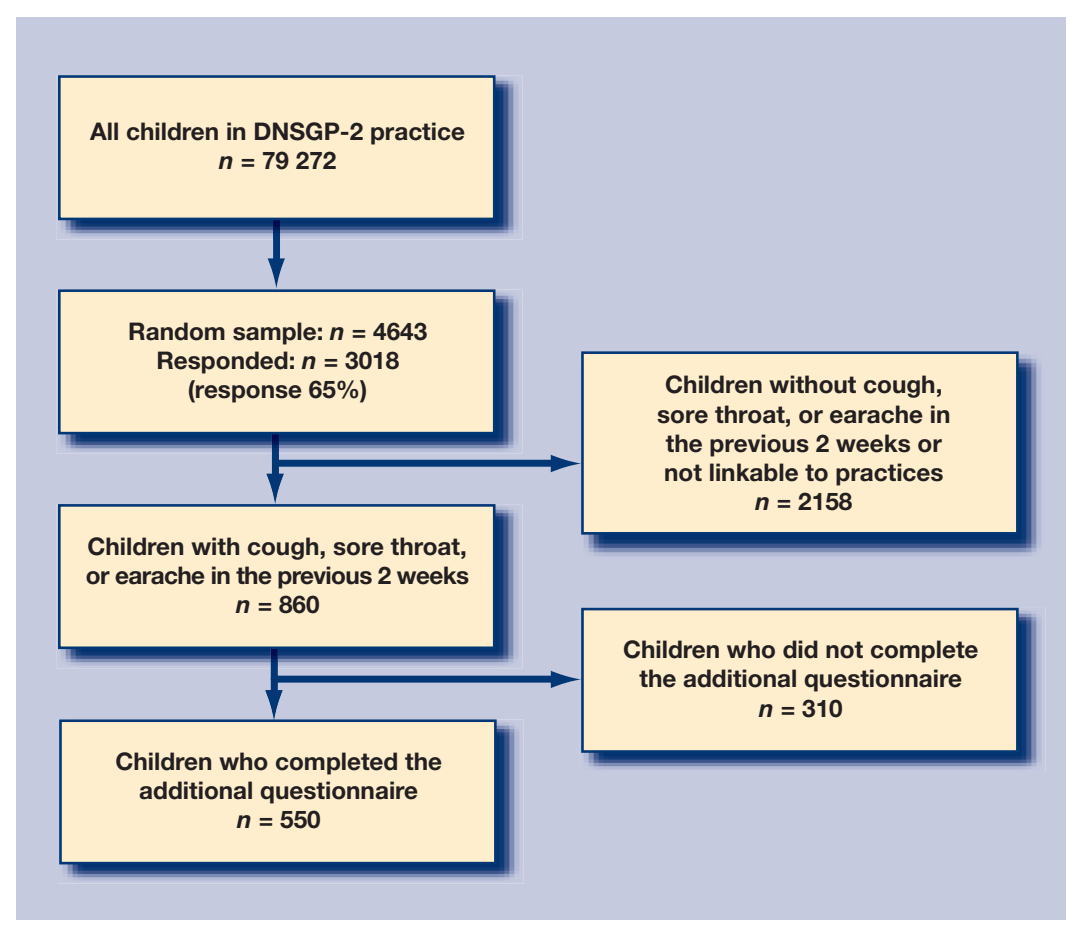


secondary school or less versus more than secondary school); type of health insurance (public versus private); degree of urbanisation of the patient's residence (rural versus urban); ethnic origin (non-native versus native); self-reported health (poor, moderate or good versus very good or excellent); and if the child had ever been diagnosed as having asthma. For all children younger than 12 years, a proxy interview was carried out with a parent; children aged 12-17 years were interviewed personally.

For all people approached for the health interview, responders and non-responders did not differ with respect to age, sex, and health insurance.

\section{Patients}

Children who had recently (in the 2 weeks preceding the interview) had cough, sore throat, or earache $(n=$ 860) were asked to complete an additional questionnaire (response rate $n=64 \%$ ). They were asked about the duration of symptoms (more or less than 2 weeks); whether they consulted their GP (either by telephone, visit to the practice, or home visit) for these symptoms during the 2 weeks preceding the interview; presence of fever; whether they were cued by their partner (only for parents), by parents, or by others to consult the GP; if they had used over-the-counter medication; and whether the parents worried that their child had a serious illness.

\section{GP characteristics}

Characteristics of all 122 GPs were obtained via a mailed questionnaire. Assessed were: age; sex; average number of patient contacts per day; singlehanded practice or not; self-reported use of national
GP guidelines (once a week or less versus more than once a week); seeing pharmaceutical representatives (an indicator of prescribing behaviour); reluctance to prescribe new drugs (entirely disagree, disagree versus hesitation, agree and entirely agree); and whether they were involved in GP training. Also calculated were the number of antibiotics prescribed by GPs for respiratory tract infections per 1000 patients of all ages during the 1-year study period.

\section{Data analysis}

Data of 550 children were included in the analysis. Because only children aged 12-17 years were personally interviewed, the two age groups $(0-11$ and 12-17 years) were also analysed separately. Patient characteristics were compared using the $\chi^{2}$ test.

The main outcome measure was whether or not the child with respiratory tract symptoms consulted their GP. Patient and GP characteristics as independent variables, and consulting the GP for respiratory symptoms as a dependent variable, were first analysed bivariately. All above-mentioned patient and GP characteristics that were associated with GP consultation (with $P<0.20$ ) were included in the multivariate logistic regression analysis. Multicollinearity tests were performed to identify unacceptably high $(>0.80)$ correlations between the independent variables. For the multivariate analysis the significance level was $P=0.05$. Analyses were conducted with the SPSS package, (version 11.0).

The multivariate analysis was repeated taking into account the multilevel structure of the data, with children clustered within practices, using the SAS package (version 8.2).

Table 1. Characteristics of all children interviewed, children with recent symptoms
(cough, sore throat, or earache), children who consulted their GP for these (cough, sore throat, or earache), children who
symptoms, and children who did not consult.

\begin{tabular}{|c|c|c|c|c|}
\hline & $\begin{array}{c}\text { All children } \\
\text { interviewed } \\
(n=3018)\end{array}$ & $\begin{array}{l}\text { Children with } \\
\text { recent symptoms } \\
(n=550)\end{array}$ & $\begin{array}{l}\text { Children with recent } \\
\text { symptoms who consulted } \\
\text { their GP }(n=147)\end{array}$ & $\begin{array}{l}\text { Children with recent } \\
\text { symptoms who did not } \\
\text { consult their GP }(n=403)\end{array}$ \\
\hline \multicolumn{5}{|l|}{ Age, years } \\
\hline $0-4(\%)$ & $768(25.4)$ & $173(31.5)$ & $53(36.1)$ & $120(29.8)$ \\
\hline $5-11(\%)$ & $1327(44.0)$ & $220(40.0)$ & $65(44.2)$ & $155(38.5)$ \\
\hline $12-17(\%)$ & $923(30.6)$ & $157(28.5)$ & $29(19.7)$ & $128(31.7)$ \\
\hline Sex (\% female) & 46.9 & 52.9 & 46.3 & 55.3 \\
\hline $\begin{array}{l}\text { Level of education parents } \\
\text { (\% low education) }\end{array}$ & 14.1 & 10.4 & 14.3 & 8.9 \\
\hline $\begin{array}{l}\text { Type of health insurance } \\
\text { (\% public insurance) }\end{array}$ & 57.6 & 56.7 & 61.2 & 55.1 \\
\hline Urban (\%) & 50.9 & 51.8 & 62.6 & 47.9 \\
\hline Ethnicity (\% native Dutch) & 90.8 & 89.5 & 87.1 & 90.3 \\
\hline $\begin{array}{l}\text { Self-reported health } \\
\text { (\% poor to good) }\end{array}$ & 40.1 & 47.3 & 63.9 & 41.6 \\
\hline
\end{tabular}




\section{RESULTS}

Patient characteristics are presented in Table 1. Young children (aged 0-4 years) more frequently had respiratory symptoms (cough, sore throat, or earache) in the previous 2 weeks than older children $(P=0.01)$. Girls more often reported respiratory symptoms than boys $(P=0.009)$. Type of health insurance and degree of urbanisation did not differ between all children interviewed and those with recent respiratory symptoms. Children with respiratory symptoms more often reported their health to be 'poor to good' than 'very good' or 'excellent'.

About $27 \%$ of the children with recent respiratory symptoms consulted their GP. Children aged 0-4 years and their parents consulted the GP more often than older children $(P=0.02)$, and children who had public health insurance were more likely to consult the GP. Children living in an urban area were over represented in the group of children with recent symptoms who consulted their GP, and the latter group more often reported their health to be 'poor to good' $(P<0.001)$.

GP characteristics are presented in Table 2. The mean age of the GPs was 47 years, less than onequarter were female, and the majority were practising in an urban area. The mean number of daily contacts was 30 , and most of the GPs reported regular use of the national general practice guidelines. Almost 50\% were GP trainers, a small majority saw pharmaceutical representatives, and most GPs were reluctant to prescribe new drugs.

Table 3 provides an overview of the patient factors related to GP consultation. Children who consulted their GP more often had symptoms that lasted longer than 2 weeks and more often reported having fever, than children who did not consult. When parents or children were cued by others to contact the GP they more frequently consulted their GP $(34.7 \%$ versus $1.0 \%)$. As stated before, for children less than 12 years of age a proxy interview was carried out; all
Table 2. Characteristics of the participating GPs $(n=122)$.

\begin{tabular}{lc} 
Mean age, years (SD) & $47.4(6.1)$ \\
\hline Sex (\% female) & 21.3 \\
\hline Single-handed practice (\%) & 33.6 \\
\hline Practice size, mean (SD) & $2330(589)$ \\
\hline Full-time equivalent, mean (SD) & $0.88(0.17)$ \\
\hline Number of daily contacts, mean (SD) & $29.7(11.9)$ \\
\hline $\begin{array}{l}\text { Consulting general practice national guidelines } \\
\text { more than once a week (\%) }\end{array}$ & 54.9 \\
\hline GP trainer (\%) & 49.2 \\
\hline Seeing pharmaceutical representatives (\%) & 57.4 \\
\hline Reluctant to prescribe new drugs (\%) & 92.6 \\
\hline Number of antibiotic prescriptions/1000 patients, mean (SD) & $265.8(132.1)$ \\
\hline
\end{tabular}

$S D=$ standard deviation

parents who felt cued to consult the GP were cued by their partner. For children older than 12 years the questionnaire was answered by the children themselves and this group were cued by their parents. Children of worried parents consulted their GP more frequently.

\section{Determinants for consulting a GP}

The results of the multivariate analyses are presented in Table 4 (all children together, and the two subgroups separately). Multicollinearity testing did not reveal any unacceptably high correlations between the independent variables. None of the correlations was above 0.30 , and most were close to zero.

For all children, seven determinants for GP consultation emerged. Younger children from urban areas with upper respiratory symptoms consulted their GP more often. Children who reported their own health as 'poor to good' consulted their GP twice as often as children reporting their health as 'very good' or 'excellent'. Symptoms lasting more than 2 weeks and presence of fever yielded an increased chance of GP consultation (odds ratios: 2.1 and 3.5 respectively). Worried parents and those who were

Table 3. Percentages of children with recent symptoms (cough, sore throat, or earache) who consulted their GP for these symptoms and children who did not.

\begin{tabular}{|c|c|c|c|}
\hline & $\begin{array}{l}\text { Children with recent } \\
\text { symptoms who consulted } \\
\text { their GP }(n=147), \%\end{array}$ & $\begin{array}{l}\text { Children with recent } \\
\text { symptoms who did not } \\
\text { consult their GP ( } n=403), \%\end{array}$ & $P$-value ${ }^{a}$ \\
\hline Symptoms $>2$ weeks & 73.2 & 28.8 & $<0.001$ \\
\hline Presence of fever during reported symptoms & 41.5 & 21.6 & $<0.001$ \\
\hline Cued by others to consult GP & 34.7 & 1.0 & $<0.001$ \\
\hline Over-the-counter medication & 60.5 & 59.3 & 0.790 \\
\hline Worried child is suffering a serious illness & 42.1 & 9.3 & $<0.001$ \\
\hline Self-reported diagnosis asthma & 25.2 & 11.2 & $<0.001$ \\
\hline
\end{tabular}

$\chi^{2}$, degree of freedom $=1$. 
Table 4. Determinants for consulting a GP for recent cough, sore throat, or earache for all children who completed questionnaires, children aged 0-11 years and children aged 12-17 years.

\begin{tabular}{|c|c|c|c|c|c|c|}
\hline & All children $(n=550)$ & & Children $0-11$ years $(n=3$ & & Children $12-17$ years $(n=1$ & \\
\hline & Adjusted OR (95\% Cl) & $P$-value & Adjusted OR (95\% Cl) & $P$-value & Adjusted OR (95\% Cl) & $P$-value \\
\hline Age & 0.91 (0.86 to 0.97$)$ & 0.002 & 0.99 (0.89 to 1.10$)$ & 0.900 & 1.05 (0.78 to 1.40$)$ & 0.770 \\
\hline Female sex & 0.91 (0.55 to 1.52$)$ & 0.720 & 0.73 (0.42 to 1.27$)$ & 0.260 & $1.22(0.46$ to 3.26$)$ & 0.690 \\
\hline Urban living & 2.01 (1.19 to 3.40$)$ & 0.009 & 2.19 (1.25 to 3.83$)$ & 0.006 & 1.31 (0.48 to 3.62$)$ & 0.600 \\
\hline Low education parents & 0.73 (0.41 to 1.32$)$ & 0.300 & 0.70 (0.36 to 1.37$)$ & 0.300 & 0.69 (0.26 to 1.81$)$ & 0.450 \\
\hline $\begin{array}{l}\text { Reporting own health as } \\
\text { poor to good }\end{array}$ & 2.23 (1.26 to 3.94$)$ & 0.006 & 1.73 (0.90 to 3.33$)$ & 0.100 & $4.00(1.43$ to 11.01$)$ & 0.008 \\
\hline $\begin{array}{l}\text { Reporting presence of } \\
\text { diagnosis asthma }\end{array}$ & 1.39 (0.71 to 2.69$)$ & 0.340 & $1.52(0.75$ to 3.11$)$ & 0.250 & 1.41 (0.41 to 4.89$)$ & 0.590 \\
\hline $\begin{array}{l}\text { Duration of symptoms } \\
>2 \text { weeks }\end{array}$ & 3.50 (1.98 to 6.19$)$ & $<0.001$ & 3.80 (2.05 to 7.03$)$ & $<0.001$ & 5.04 (1.69 to 14.99$)$ & 0.004 \\
\hline Fever & 2.11 (1.22 to 3.64$)$ & 0.007 & 2.56 (1.42 to 4.61$)$ & 0.002 & 2.38 (0.79 to 7.13$)$ & 0.120 \\
\hline $\begin{array}{l}\text { Parents worried } \\
\text { (or child if } \geq 12 \text { years) }\end{array}$ & 4.95 (2.79 to 8.78$)$ & $<0.001$ & 4.88 (2.61 to 9.12$)$ & $<0.001$ & 2.77 (0.81 to 9.48$)$ & 0.100 \\
\hline Cued by others to visit GP & $47.72(15.34$ to 148.48$)$ & $<0.001$ & 12.34 (3.86 to 39.51$)$ & $<0.001$ & $--^{a}$ & - \\
\hline GPs' age & 0.98 (0.94 to 1.03$)$ & 0.400 & $0.98(0.93$ to 1.03$)$ & 0.360 & 0.99 (0.91 to 1.07$)$ & 0.780 \\
\hline $\begin{array}{l}\text { Consulting general practice } \\
\text { national guidelines more } \\
\text { than once a week }\end{array}$ & 0.67 (0.40 to 1.12$)$ & 0.120 & 0.76 (0.44 to 1.31$)$ & 0.320 & 0.40 (0.15 to 1.03$)$ & 0.590 \\
\hline
\end{tabular}

Multivariate logistic regression analysis. ${ }^{a}$ Not included in analysis: every child that was cued consulted the GP. OR $=$ odds ratio.

cued by other family members to consult a GP consulted their GP more often.

In the subgroup of children aged 0-11 years, fewer independent determinants were associated with GP consultation. Children who consulted a GP more frequently, more often had fever, respiratory symptoms lasting longer than 2 weeks, and more frequently lived in urban areas. Parents of these children were more frequently worried and cued to consult a GP with their child.

In the subgroup of children aged 12-17 years, the two independent determinants 'reporting own health as moderate to poor' and 'longer duration of respiratory symptoms' were related with GP consultation. This subgroup was analysed without the determinant 'cued to consult the GP' because every child in this age group who was cued did in fact consult the GP.

None of the GP characteristics were associated with the consulting pattern of the children and their parents. Multilevel analyses, taking clustering of children at practice level into account, yielded very similar results.

\section{DISCUSSION}

\section{Summary of main findings}

Younger children more often consulted their GP for respiratory symptoms than older ones. Children with fever and respiratory symptoms that lasted longer than 2 weeks, more often consulted their GP. GPs were more frequently consulted when the parents were worried and when children and/or parents were cued by other family members. Children with respiratory symptoms living in urban areas consulted more often than children in rural areas. Fever and longer duration of respiratory symptoms were associated with consulting behaviour, whereas GPrelated characteristics were not associated with parents' decision to consult.

\section{Strengths and limitations of the study}

This study uses data derived from the Second Dutch National Survey of General Practice (DNSGP-2). These unique data allowed for the assessment of the role of both child and parent factors, as well as GP characteristics, on consulting behaviour for respiratory tract symptoms.

Characteristics of the GP and patient sample are comparable with the general Dutch population. ${ }^{19}$ Only single-handed practices were relatively underrepresented; however, because this item was not related to the study outcome it is probably not a major limitation. The results therefore can be assumed to represent daily primary care and consultation behaviour in the Netherlands.

Although the children were separated into two age groups (driven by the different way of data collection in the health interview), within each age group differences may still exist.

In the additional questionnaire, parents and 
children were asked whether or not they had consulted their GP. Self-reports are vulnerable to recall bias. Because the recall period was only 2 weeks, it can be assumed that this bias was relatively small.

\section{Comparison with existing literature}

A relationship between age and consultation rates was reported earlier by Holme. ${ }^{20}$ Bruijnzeels et al found that younger children (aged 0-4 years old) were taken twice as often to their GP than older children (aged 10-14 years). ${ }^{2}$ The current study yields similar results; with every yearly increase in age the risk for a child with respiratory symptoms to consult the GP decreases by $9 \%$. In accordance with Hay et al, it was found that fever plays an important role in consultation. ${ }^{21}$ In contrast with the current study in which children from urban areas more frequently consulted their GP with cough, sore throat, and earache, Bruijnzeels et al found no relation with the degree of urbanisation. ${ }^{2}$

Van Duijn et al reported that age, longer duration of symptoms, and having respiratory comorbidity positively influences GP consultation among adults with upper respiratory tract symptoms. ${ }^{14}$ Adult patients who were worried about the seriousness of their respiratory symptoms consulted a GP earlier, and the same was found for those who were cued by others to visit a GP. ${ }^{14,22}$ This study showed similar findings for children aged 0-17 years old.

The literature is not conclusive concerning whether GP characteristics are associated with GP consultation by children and parents. In this study no GP-related determinants were found for GP consultation, as was reported earlier for adults. ${ }^{14}$ In another study, GP characteristics were associated with prescribing antibiotics for upper respiratory tract infections. ${ }^{23}$ Others found the same association, ${ }^{24-26}$ which may be explained as follows: patients generally know the prescription pattern of their GP and this may, in turn, affect GP consultation rates. However, in contrast to these studies, the current study combined both patient viewpoints with respect to a specific respiratory tract infection and GP characteristics. Williamson et al reported that prescribing antibiotics for middle ear disease probably increased reattendance. ${ }^{27}$

In this study no association was found between the number of antibiotics prescribed by GPs for respiratory tract infection per 1000 patients and GP consultation. This difference perhaps can be explained by the larger range of antibiotic prescriptions in the UK.

Being cued by a family member to consult the GP is a well-known phenomenon in daily practice. In this study parents cued each other, and older children were cued by their parents. This strong association between 'cueing by family members' and GP consultation confirms the findings of Cardol et al which examined family influence on healthcare utilisation. ${ }^{28}$

\section{Implications for clinical practice}

This study emphasises the importance of adequately exploring the reasons for consulting the GP. For example: are children and/or parents worried about the child's respiratory symptoms? Are they cued by another family member? Is the fever or duration of symptoms the reason for consulting the GP? Most symptoms of cough, sore throat, and earache have a viral cause and a self-limiting character. When GPs pay more attention to the possible reasons for consultation, they will be able to give more appropriate advice and reassurance to children and parents about these specific symptoms.

In conclusion, this study shows that children with younger age, fever, longer duration of upper respiratory tract symptoms, those living in an urban area, along with parents and children who worry about symptoms reporting their own health as 'poor to good', and those who are cued by other family members consult their GP more frequently. Knowledge about these determinants will enable GPs to provide appropriate and timely advice and reassurance.

\section{Funding body}

The Dutch ministry of Health, Welfare and Sports mainly funded the surveys directly or indirectly. In addition, the 'Stichting Centraal Fonds RVVZ' contributed financially to the second survey. The analysis reported in this paper was made possible through internal funding of the department of General Practice, Erasmus MC-University Medical Center Rotterdam

\section{Competing interests}

The authors have stated that there are none

\section{Acknowledgements}

The authors thank Sten Willemsen, Department of General Practice, Erasmus MC-University Medical Center Rotterdam, for his statistical assistance.

\section{Discuss this article}

Contribute and read comments about this article on the Discussion Forum: http://www.rcgp.org.uk/bjgp-discuss

\section{REFERENCES}

1. Ashworth M, Charlton J, Ballard $\mathrm{K}$, et al. Variations in antibiotic prescribing and consultation rates for acute respiratory infection in UK general practices 1995-2000. Br J Gen Pract 2005; 55(517): 603-608.

2. Bruijnzeels MA, Foets M, van der Wouden JC, et al. Everyday symptoms in childhood: occurrence and general practitioner consultation rates. Br J Gen Pract 1998; 48(426): 880-884.

3. Otters HB, van der Wouden JC, Schellevis FG, et al. Changing morbidity patterns in children in Dutch general practice: 1987-2001. Eur J Gen Pract 2005; 11(1): 17-22.

4. Nyquist AC, Gonzales R, Steiner JF, Sande MA. Antibiotic prescribing for children with colds, upper respiratory tract infections, and bronchitis. JAMA 1998; 279(11): 875-877.

5. Del Mar CB, Glasziou PP, Spinks AB. Antibiotics for sore throat Cochrane Database Syst Rev 2006; 4: CD000023.

6. Fahey T, Smucny J, Becker L, Glazier R. Antibiotics for acute 
bronchitis. Cochrane Database Syst Rev 2004; 4: CD000245.

7. Glasziou PP, Del Mar CB, Sanders SL, Hayem M. Antibiotics for acute otitis media in children. Cochrane Database Syst Rev 2004; 1: CD000219.

8. Damoiseaux RAMJ, van Balen FAM, Leenheer WAM, Kolnaar BGM. NHG guidelines on acute otitis media. Huisarts Wet 2006; 49: 615-621.

9. Verheij ThJM, Salomé PhL, Bindels PJ, et al. NHG guidelines on acute cough. Huisarts Wet 2003; 46: 496-506.

10. Zwart S, Dagnelie CF, Van Staay BK, et al. NHG guidelines on acute sore throat. Huisarts Wet 2007; 50: 59-68.

11. Kumar S, Little P, Britten N. Why do general practitioners prescribe antibiotics for sore throat? Grounded theory interview study. BMJ 2003; 326(7381): 138 .

12. Welschen I, Kuyvenhoven M, Hoes A, Verheij T. Antibiotics for acute respiratory tract symptoms: patients' expectations, GPs' management and patient satisfaction. Fam Pract 2004; 21(3): 234-237.

13. Van Duijn HJ, Kuyvenhoven MM, Schellevis FG, Verheij TJ. Views on respiratory tract symptoms and antibiotics of Dutch general practitioners, practice staff and patients. Patient Educ Couns 2006; 61(3): 342-347.

14. Van Duijn HJ, Kuyvenhoven MM, Schellevis FG, Verheij TJ. Illness behaviour and antibiotic prescription in patients with respiratory tract symptoms. Br J Gen Pract 2007; 57(540): 561-568.

15. Ashworth M, Godfrey E, Harvey K, Darbishire L. Perceptions of psychological content in the GP consultation - the role of practice, personal and prescribing attributes. Fam Pract 2003; 20(4):373-375.

16. Britt HC, Valenti L, Miller GC. Determinants of consultation length in Australian general practice. Med J Aust 2005; 183(2): 68-71.

17. Britt $\mathrm{H}$, Bhasale A, Miles DA, et al. The sex of the general practitioner: a comparison of characteristics, patients, and medical conditions managed. Med Care 1996; 34(5): 403-415.

18. Westert GP, Schellevis FG, de Bakker DH, et al. Monitoring health inequalities through general practice: the Second Dutch National Survey of General Practice. Eur J Public Health 2005; 15(1): 59-65.
19. Schellevis FG, Westert GP, de Bakker DH, Groenewegen PP. Tweede nationale studie naar ziekten en verrichtingen in de huisartspraktijk. Vraagstellingen en methoden [The Second Dutch National Survey of General Practice]. Objectives and methods. Utrecht/Bilthoven: NIVEL/RIVM, 2004

20. Holme CO. Incidence and prevalence of non-specific symptoms and behavioural changes in infants under the age of two years. Br J Gen Pract 1995; 45(391): 65-69.

21. Hay AD, Heron J, Ness A, ALSPAC study team. The prevalence of symptoms and consultations in pre-school children in the Avon Longitudinal Study of Parents and Children (ALSPAC): a prospective cohort study. Fam Pract 2005; 22(4): 367-374.

22. Eriksson T, Maclure M, Kragstrup J. Consultation with the general practitioner triggered by advice from social network members. Scand J Prim Health Care 2004; 22: 54-59.

23. Jaye $\mathrm{C}$, Tilyard $\mathrm{M}$. A qualitative comparative investigation of variation in general practitioners' prescribing patterns. Br J Gen Pract 2002; 52(478): 381-386.

24. Kuyvenhoven M, de Melker R, van der Velden K. Prescription of antibiotics and prescribers' characteristics. A study into prescription of antibiotics in upper respiratory tract infections in general practice. Fam Pract 1993; 10(4): 366-370.

25. De Sutter AI, De Meyere MJ, De Maeseneer JM, Peersman WP. Antibiotic prescribing in acute infections of the nose or sinuses: a matter of personal habit? Fam Pract 2001; 18(2): 209-213.

26. Akkerman AE, Kuyvenhoven MM, van der Wouden JC, Verheij TJ. Prescribing antibiotics for respiratory tract infections by GPs: management and prescriber characteristics. Br J Gen Pract 2005; 55(511): 114-118.

27. Williamson I, Benge S, Mullee M, Little P. Consultations for middle ear disease, antibiotic prescribing and risk factors for reattendance: a caselinked cohort study. Br J Gen Pract 2006; 56(524): 170-175.

28. Cardol M, Groenewegen PP, de Bakker DH, et al. Shared help-seeking behaviour within families: a retrospective cohort study. BMJ 2005; 330(7496): 882. 